\title{
Effect of variations in the riveting process on the quality of riveted joints
}

\author{
S. Hossein Cheraghi • K. Krishnan • Bijay Bajracharya
}

Published online: 5 July 2008

(C) Springer-Verlag London Limited 2008

Erratum to: Int J Adv Manuf Technol

DOI 10.1007/s00170-007-1291-6

Unfortunately, two of the authors were omitted in the original article.

The correct information is given below

K. Krishnan

Industrial and Manufacturing Engineering Wichita State University

Bijay Bajracharya

Genie - a Terex Company

The online version of the original article can be found at http://dx.doi. org/10.1007/s00170-007-1291-6.

\footnotetext{
S. H. Cheraghi $(\bowtie) \cdot$ K. Krishnan

Industrial and Manufacturing Engineering,

Wichita State University,

1845 Fairmont,

Wichita, KS 67260-0035, USA

e-mail: hossein.cheraghi@wichita.edu

B. Bajracharya

Genie - a Terex Company,

P.O. Box 97030,

Redmond, WA 98073, USA 